\title{
Safe and effective deodorization of malodorous fungating tumors using topical metronidazole $0.75 \%$ gel (GK567): a multicenter, open-label, phase III study (RDT.07.SRE.27013)
}

\author{
Kazuhiro Watanabe $^{1}$ - Arata Shimo ${ }^{2}$ - Kouichiro Tsugawa ${ }^{2}$ Yutaka Tokuda $^{3}$. \\ Hideko Yamauchi $^{4}$ - Eriko Miyai ${ }^{5}$. Kimitoshi Takemura ${ }^{5}$ - Akihiko Ikoma ${ }^{5}$. \\ Seigo Nakamura ${ }^{6}$
}

Received: 17 June 2015 / Accepted: 21 December 2015 / Published online: 30 December 2015

(C) The Author(s) 2015. This article is published with open access at Springerlink.com

\begin{abstract}
Purpose Malignant fungating tumors are neoplastic tumors associated with skin ulcers, which are susceptible to microbial colonization. Bacterial infection and proliferation may lead to malodor causing distress to patients. Metronidazole - an effective agent against anaerobes - may contribute to deodorization and improvement in quality of life (QOL). This study investigated the efficacy and safety of topical metronidazole $0.75 \%$ gel for alleviation of malodor in anaerobically infected fungating neoplastic tumors.

Methods This was a multicenter, open-label, non-controlled, phase III study including subjects aged 20 years or older with
\end{abstract}

Eriko Miyai

eriko.miyai@galderma.com

1 Education and Research Center for Clinical Pharmacy, Showa Pharmaceutical University, 3-3165 Higashi-Tamagawagakuen, Machida-shi, Tokyo 194-8543, Japan

2 Department of Breast Endocrine Surgery, St. Marianna University School of Medicine, 2-16-1 Sugao, Miyamae-ku, Kawasaki, Kanagawa 216-8511, Japan

3 Department of Surgery, Tokai University School of Medicine, 143 Shimokasuya, Isehara, Kanagawa 259-1193, Japan

4 Department of Breast Surgical Oncology, St. Luke's International Hospital, 9-1 Akashi-cho, Chuo-ku, Tokyo 104-8560, Japan

5 Galderma K.K., Shinjuku Grand Tower 34F, 8-17-1 Nishi-Shinjuku, Shinjuku-ku, Tokyo 160-6134, Japan

6 Department of Surgery, Division of Breast Surgical Oncology, Showa University Hospital, 1-5-8 Hatanodai,

Shinagawa-ku, Tokyo 142-8666, Japan cutaneous fungating tumors releasing malodor (minimum score of 2 (mildly offensive smell) on a scale from 0 (no smell) to 4 (extremely offensive smell) based on investigator's assessment). Subjects applied metronidazole $0.75 \%$ gel once or twice daily at the investigator's discretion for 14 days. Success was defined as an odor score of 0 or 1 at day 14, as assessed by the investigator. Patient satisfaction was assessed using a satisfaction questionnaire. Adverse events (AEs) that occurred after application of metronidazole $0.75 \%$ gel were also reported.

Results A total of 21 subjects at a median age of 65.0 years were enrolled. The success rate of deodorization at day 14 was $95.2 \%$ (20/21 subjects). The patient satisfaction assessment showed that $71.4 \%(15 / 21)$ of subjects were markedly or moderately improved. The treatment was well tolerated with only two AE cases of skin neoplasm bleeding (one mild and one moderate).

Conclusions Metronidazole $0.75 \%$ gel is an effective and safe treatment for deodorization of malodorous fungating tumors.

Keywords Topical metronidazole $\cdot$ Malodorous fungating tumors $\cdot$ Odor $\cdot$ Skin ulcer $\cdot$ Clinical trial

\section{Introduction}

Malodors associated with ulcerating tumors are reportedly caused by the odor of anaerobic infections of fungating wounds and the odor of fatty acids produced in necrotizing cancer tissue [1, 2]. In addition to emotional distress caused by the appearance of the fungating wound, the large amount of exudate, pain, and constant bleeding risk, patients with malodorous fungating tumors also suffer from low self-esteem, 
social isolation, and low quality of life (QOL) [3]. Furthermore, the families and medical caregivers of patients with malodorous fungating tumors may avoid close interactions with the patient due to the odor.

It is well known that anaerobic bacteria cause malodors in fungating wounds and that the antibacterial drug metronidazole (MTZ) is effective for treating malodorous fungating wounds $[4,5]$. Furthermore, the topical application of MTZ is recommended in Symptom Relief in Terminal Illness, published by the World Health Organization (WHO; WHO Library Cataloging-inPublication Data, 1998) and the 2001 curriculum "Optimizing Cancer Care: The Importance of Symptom Management," published by the American Society of Clinical Oncology (ASCO) [3, 6, 7]. Topical MTZ has been approved and marketed for the treatment of malodorous fungating wounds only in the United Kingdom (UK). In Japan, where topical MTZ is yet to be approved, each medical institution prepares special topical MTZ formulations for patients with malodorous fungating tumors $[5,8$, 9].

In 2006, we surveyed medical facilities certified by the Japanese Breast Cancer Society to understand the current prescription status and dosage of topical MTZ formulations for patients with malodorous fungating wounds due to breast cancer. Data from 313 responding facilities revealed that $80(26 \%)$ facilities formulated topical MTZ for malodorous fungating wounds in patients with breast cancer [10]. Also in 2010, the Japanese Society of Hospital Pharmacists surveyed 382 member institutions about the use and preparation of topical agents for patients with malodorous fungating tumors and revealed that 317 $(83 \%)$ of the institutions used or prepared topical agents for malodorous fungating wounds. Among the 317 institutions, $264(83 \%)$ formulated topical MTZ and 266 (84\%) await commercialization [11].

To realize the commercialization of topical MTZ, the Japanese Society for Palliative Medicine and the Japanese Society for Pharmaceutical Palliative Care and Sciences filed a petition to the Ministry of Health, Labour and Welfare (MHLW) in 2010. Based on the discussion in the 6th Evaluation Committee on Unapproved or Off-label Drugs with High Medical Needs, ${ }^{1}$ MHLW commissioned the Galderma Company (Tokyo, Japan) to develop topical MTZ. Galderma agreed to the commission and subsequently conducted a phase III clinical study to investigate the efficacy and safety of topical MTZ $0.75 \%$ gel (GK567) in patients with malodorous fungating tumors.

\footnotetext{
${ }^{0}$ Ministry of Health, Labour and Welfare, the 6th Evaluation Committee on Unapproved or Off-label Drugs with High Medical Needs, http:// www.mhlw.go.jp/stf/shingi/2r9852000000wlaz.html
}

\section{Methods}

\section{Trial design}

An open-label, uncontrolled, multicenter, phase III study was conducted from April to December 2012 to evaluate the efficacy and safety of MTZ $0.75 \%$ gel (GK567) applied for 14 consecutive days.

\section{Participants}

Study participants met the following criteria: in- or outpatients aged $\geq 20$ years with fungating tumors that were possibly infected; malodor corresponding to 2 or higher on the odor scale of $0-4$ as judged by the investigators; skin ulceration requiring a daily dose of $\leq 30 \mathrm{~g}$ MTZ $0.75 \%$ gel (for patients with breast cancer, the ulcer size should be smaller than one of the breasts); an Eastern Cooperative Oncology Group (ECOG) performance status of $\leq 3$; and an anticipated survival of $\geq 3$ months.

Exclusion criteria were the following: (1) current systemic administration of antibiotics or administration in the last 2 weeks; (2) current local or extended application of MTZ $0.75 \%$ gel or other topical antibacterial agents in the past week; (3) current administration of topical agents for fungating tumors; (4) patients with a scheduled change in concurrent cancer therapy during the study period; (5) those with malodorous fungating wounds not in contact with tumor tissue or those with fungating tumors invading bone tissue; (6) allergy or hypersensitivity to MTZ; (7) using ritonavir, disulfiram, warfarin, or lithium (these interact with MTZ) or unable to abstain from alcohol during the study period; (8) serious cardiovascular diseases, hemodyscrasia (except for idiopathic thrombocytopenic purpura), or central or peripheral organic neurological disorders; or (9) pregnant or breastfeeding women or women planning to conceive during the study period.

\section{Intervention}

After removing the container label, Rozex ${ }^{\circledR}$ gel $0.75 \%$ (Galderma) was used as the MTZ $0.75 \%$ gel in the present study. MTZ $0.75 \%$ gel was applied once or twice daily up to a maximum daily dose of $30 \mathrm{~g}$ for 14 days. Fungating wounds were cleaned thoroughly and covered with a dressing material such as gauze, silicon gauze, or wound dressing coated with topical MTZ.

The systemic and topical antibiotics administration and any topical treatments on the fungating wound, excepting MTZ $0.75 \%$ gel, were prohibited during the drug application period. 


\section{Primary endpoints: improvement of score of odor}

At the time of screening, before (baseline or day 0 ) and after application of MTZ $0.75 \%$ gel (days 7 and 14), the malodor of fungating wounds was scored by the investigators, nurses (or study coordinators), and patients on 5 scale of 0 to 4 $(0=$ no smell; $1=$ smell present but not offensive, slight smell close to the ulcer about $20 \mathrm{~cm} ; 2$ = mildly offensive smell, more pronounced smell close to the ulcer about $20 \mathrm{~cm}$; 3 = moderately offensive smell, at the bedside about $1 \mathrm{~m}$; 4 = extremely offensive smell, at the entrance of the room). The success rate was defined as the percentage of patients whose odor was scored 0 or 1 by investigators on day 14 (or at the time of premature study termination).

\section{Secondary endpoints}

\section{Clinical examination of fungating wounds}

At the time of screening, on day 0 (pre-administration baseline), and on post-administration days 7 and 14, fungating wounds were evaluated by investigators based on 4 scale on frequency of dressing changes of 0 to $3(0=$ none, no discharge/once daily; $1=$ mild, dressing need to be changed twice daily; 2 = moderate, dressing need to be changed 3 times daily; $3=$ marked, dressing need to be changed $>3$ times daily $/$ bloody). The amount of exudate was assessed by examining the frequency of dressing changes per day. The nature of the exudate, such as purulent, serous or blood-stained fluid, was recorded.

\section{Pain assessment}

At the time of screening and on days 0,7 , and 14, the patients evaluated pain of the fungating wound in the last $24 \mathrm{~h}$ using a 100 -mm visual analog scale (VAS) (0 mm, no pain; $100 \mathrm{~mm}$, worst imaginable pain).

\section{Bacteriological testing}

On days 0 and 14 (or at the time of premature study termination), samples were collected from the area of the wound with the most severe inflammation and exudate (usually around the center) for the identification and semi-quantitation of the causal bacteria.

\section{Overall improvement in patient satisfaction}

After clinical examination on day 14 (or at the time of premature study termination), a patient satisfaction survey was conducted with the involvement of patients and/or their families. By comparing the data with baseline data, the investigator categorized the change in patient satisfaction as markedly improved, moderately improved, slightly improved, no change, or worsened.

\section{Pharmacokinetics}

To measure the plasma concentration of MTZ and estimate the total drug exposure around the time of its peak $\left(T_{\max }\right)$, blood was sampled before and after (at two time points between 2$8 \mathrm{~h}$ ) the application of MTZ $0.75 \%$ gel on day 7 and at the time of hospital arrival on day 14. A validated highperformance liquid chromatographic method (limit of quantitation, $2 \mathrm{ng} / \mathrm{mL}$ ) was used to determine the plasma concentrations and pharmacokinetic parameters of MTZ: $C_{\text {trough }}, C_{\max }$, $T_{\max }$, and partial AUC for day 7 and $C_{\text {trough }}$ for day 14 .

\section{Safety}

Adverse events were recorded during drug application. In addition, hematological (white blood cell, red blood cell, hemoglobin, hematocrit, and platelet) and blood chemistry (creatinine, urea nitrogen, total bilirubin, glutamic-oxaloacetic transaminase (aspartate aminotransferase), glutamic-pyruvic transaminase (alanine aminotransferase), lactate dehydrogenase, $\gamma$ glutamyl transpeptidase, and alkaline phosphatase) examinations were performed on days 0 (baseline) and 14 (or at the time of premature study termination).

\section{Sample size}

Odor improvement was considered to be successful if scored 0 or 1 by the investigator on day 14 or at the time of premature study termination, and the proportion of patients with an odor score of 0 or 1 was defined as the success rate. The present clinical study was designed to test our hypothesis that the success rate would not fall below $70 \%$. Based on the report of Finlay et al. [12], the improvement rate would be estimated at approximately $90 \%$ after a 2 -week application. To verify with a probability of $90 \%$ that the $95 \%$ confidence interval (one side) would exceed $70 \%$, the required sample size was 20 patients, as determined using normal approximation to the binomial distribution.

\section{Ethical considerations}

This study was approved by the internal review board of each institution and performed in accordance with the Declaration of Helsinki and the Ministerial Ordinance on Good Clinical Practice for Drugs (GCP) of Japan. Informed consent was obtained from all individual participants included in the study. 


\section{Results}

\section{Subjects}

Subjects were 21 patients with breast cancer (median age, 65.0 years; range, 39-82 years), of which 20 completed the study. The application of MTZ $0.75 \%$ gel was discontinued in one patient on day 7 because of an increase in the amount of exudate from the fungating wound. Because no significant deviations from the original clinical trial implementation plan were observed, data from all 21 patients were used in the analysis of drug safety.

Demographics and baseline characteristics are shown in Table 1; $5(23.8 \%)$ patients had stage III tumors and $16(76.2 \%)$ had stage IV. The mean area of the fungating wounds was $68.6 \pm 35.4 \mathrm{~cm}^{2}$ (range, 4$\left.140 \mathrm{~cm}^{2}\right)$, and $16(76.2 \%)$ patients had not received previous treatment for malodor due to the fungating tumor (Table 1).

Table 1 Patient characteristics $(n=21)$

\begin{tabular}{|c|c|c|}
\hline & & $\begin{array}{l}\text { Number of } \\
\text { patients (\%) }\end{array}$ \\
\hline \multirow[t]{2}{*}{ Sex } & Male & 0 \\
\hline & Female & $21(100.0)$ \\
\hline Race & Asian & $21(100.0)$ \\
\hline \multirow[t]{9}{*}{ Age (year) } & Median & 65.0 \\
\hline & Range & $39-82$ \\
\hline & Mean \pm SD & $64.4 \pm 12.2$ \\
\hline & $<30$ & 0 \\
\hline & 30 to $<40$ & $1(4.8)$ \\
\hline & 40 to $<50$ & $2(9.5)$ \\
\hline & 50 to $<60$ & $3(14.3)$ \\
\hline & 60 to $<70$ & $8(38.1)$ \\
\hline & $\geq 70$ & $7(33.3)$ \\
\hline \multirow[t]{3}{*}{ Height (cm) } & Mean \pm SD & $154.51 \pm 5.44$ \\
\hline & Median & 154.10 \\
\hline & Range & $145.0-166.0$ \\
\hline \multirow[t]{3}{*}{ Weight (kg) } & Mean \pm SD & $52.67 \pm 9.38$ \\
\hline & Median & 50.00 \\
\hline & Range & $35.6-79.6$ \\
\hline \multirow[t]{2}{*}{ Previous treatment for odor } & No & $16(76.2)$ \\
\hline & Yes & $5(23.8)$ \\
\hline \multirow[t]{2}{*}{ Tumor stage } & Stage III & $5(23.8)$ \\
\hline & Stage IV & $16(76.2)$ \\
\hline \multirow[t]{2}{*}{ Tumor type (location) } & Breast cancer & $21(100.0)$ \\
\hline & Other cancer & 0 \\
\hline \multirow[t]{3}{*}{ Area of fungating wound $\left(\mathrm{cm}^{2}\right)$} & Mean \pm SD & $68.6 \pm 35.4$ \\
\hline & Median & 75.0 \\
\hline & Range & $4-140$ \\
\hline
\end{tabular}

\section{Application of study drug}

The mean duration of MTZ $0.75 \%$ gel application was $13.8 \pm 1.6$ days, and the total dose was $311.7 \pm 96.8 \mathrm{~g}$. The gel was applied $1.46 \pm 0.41$ times daily up to a daily dose of $22.6 \pm 6.4 \mathrm{~g}$ (range, $11-30 \mathrm{~g}$ ).

\section{Primary endpoint: improvement of odor score}

The odor scores given by the principal investigator on day 14 are shown in Table 2. The clinical success rate (score 0 or 1) was $95.2 \%$ (20 of 21 patients), and the $90 \%$ confidence interval (exact two-tailed significance level) was 79.3$99.8 \%$, verifying the study hypothesis that the rate of success would not fall below $70 \%$.

Differences in scores given by different evaluators are shown in Fig. 1. The scores were comparable between the investigators and nurses. The scores given by patients were slightly less than those given by the investigators or nurses. However, the temporal profiles of changes in scores were similar among the three groups.

\section{Secondary endpoints}

\section{Clinical findings of fungating wounds}

The mean \pm SD odor scores of fungating wounds were $1.6 \pm 0.9$ for day $0,1.1 \pm 1.0$ for day 7 , and $0.9 \pm 0.9$ for day 14. Exudate was characterized as purulent in 6 patients, serous fluid with blood in 5 , and serous in 4 on day 0 ; serous in 12 patients on day 7; and serous in 10 patients on day 14, demonstrating an overall reduction in purulent fluid and an increase in serous fluid during the study.

\section{Pain}

On the VAS, the mean \pm SD of pain was $28.3 \pm 29.1 \mathrm{~mm}$ on day 0 (baseline), $25.9 \pm 27.1$ on day 7 , and $22.2 \pm 25.3$ on day 14 , showing no change from baseline to day 7 or day 14 .

Table 2 Evaluation of odor by investigators ${ }^{\mathrm{a}},(n=21)$

\begin{tabular}{lll}
\hline & & Number (\%) \\
\hline Score by investigator & 0 & $13(61.9)$ \\
& 1 & $7(33.3)$ \\
2 & 0 \\
3 & $1(4.8)$ \\
& 4 & 0 \\
\hline
\end{tabular}

Mean $\pm \mathrm{SD}, 0.5 \pm 0.7$

${ }^{\mathrm{a}}$ On day 14 or at the time of premature study termination 

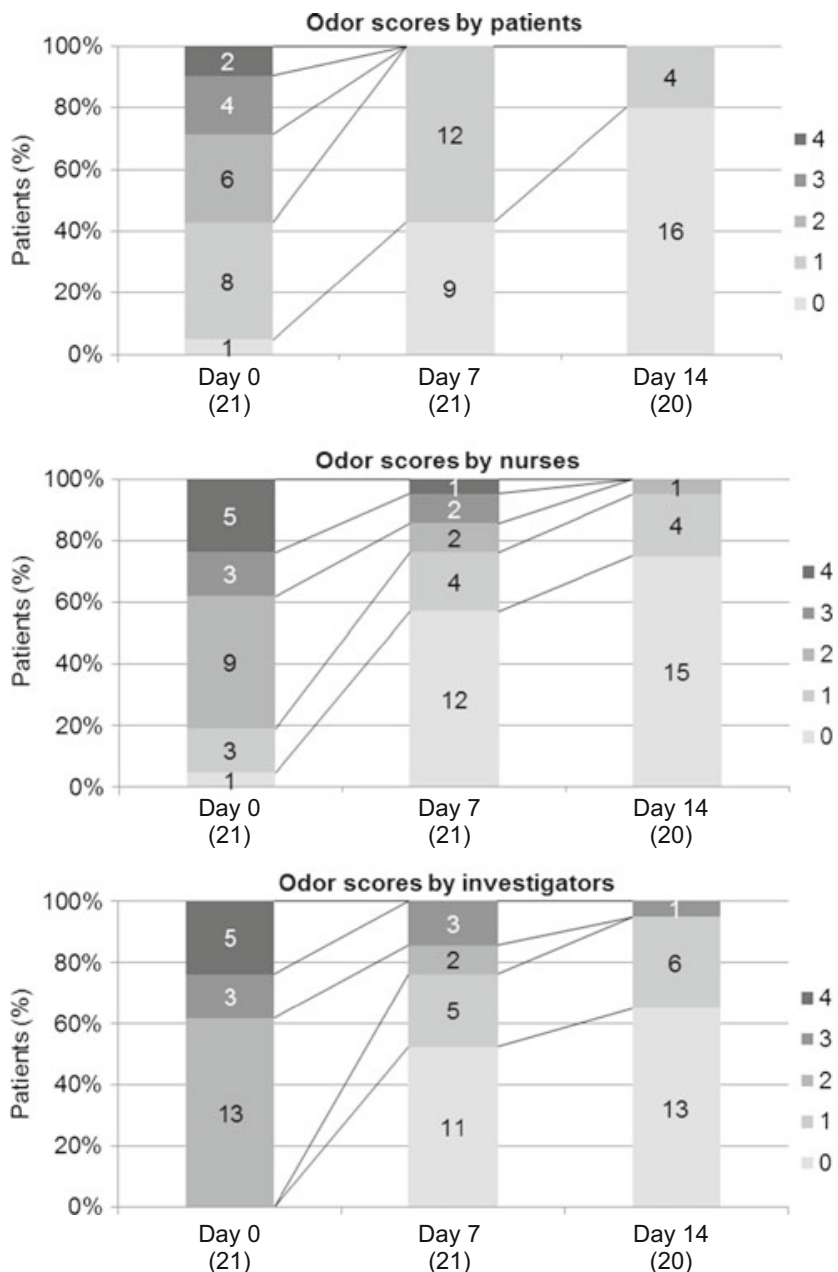

Fig. 1 Odor scores by patients, nurses, and investigators. 0 no smell; 1 smell present but not offensive, slight smell close to the ulcer about $20 \mathrm{~cm} ; 2$ mildly offensive smell, more pronounced smell close to the ulcer about $20 \mathrm{~cm} ; 3$ moderately offensive smell, at the bedside about $1 \mathrm{~m} ; 4$ extremely offensive smell, at the entrance of the room. ()$=n$

\section{Bacteriological findings}

Changes in bacteriological findings and identified bacteria are shown in Tables 3, respectively. Anaerobic bacteria detected in nine patients on day 0 were not detected on day 14 (or at the time of premature study termination). However, one novel anaerobic bacterium was detected in one of the patients on day 14 (or at the time of termination). No significant changes were observed in the profiles of aerobic bacteria.

\section{Overall improvement in patient satisfaction}

Table 4 shows the patient satisfaction on day 14 (or at the time of premature study termination). Improvement in patient satisfaction was graded as markedly or moderately improved in 15 patients $(71.4 \%)$, indicating that patients were satisfied with the efficacy of MTZ $0.75 \%$ gel for malodorous fungating tumors.

\section{Pharmacokinetics}

The pharmacokinetic parameters of MTZ are shown in Table 5. On day 7, the mean $C_{\max }$ of MTZ was $852 \mathrm{ng} / \mathrm{mL}$ (range, $136-2872 \mathrm{ng} / \mathrm{mL}$ ). The mean $C_{\text {trough }}$ was $380 \pm 281 \mathrm{ng} / \mathrm{mL}$ on day 7 and $510 \pm 565 \mathrm{ng} / \mathrm{mL}$ on day 14 . The coefficient of variance of $C_{\max }$ was $82 \%$ on day 7 , and that of $C_{\text {trough }}$ was 74 and $111 \%$ on day 7 and day 14 , respectively, showing a large variance in the pharmacokinetic parameters. This suggests a large variation in the plasma concentrations of MTZ existed among the patients.

\section{Safety}

In total, 28 adverse events were observed in 15 patients $(71.4 \%)$; only two of these were bleeding from neoplastic skin lesions (one mild and one moderate severity), which were considered to be related to MTZ $0.75 \%$ gel by the investigator and the other AEs were unrelated. Three serious AEs in one patient (4.8\%) were observed, but these were judged to be unrelated to MTZ $0.75 \%$ gel; one of these occurred prior to application of the drug. No deaths were reported in the study.

\section{Discussion}

In this study, the safety and efficacy of 14-day consecutive use of topical MTZ $0.75 \%$ gel on malodorous fungating wounds were investigated in 21 female patients with breast cancer. The subjects of this study were patients with a fungating tumor and malodor from infection, and other types of malodorous fungating tumors were not evaluated. In Japan, most studies have investigated the effects of topical MTZ on malodorous fungating tumors of breast cancer patients [5, 8, 13-29], but few investigated the efficacy and safety of topical MTZ on malodorous fungating wounds that are unrelated to breast cancer [30-34].

The mean size of skin ulceration was $68.6 \pm 35.4 \mathrm{~cm}^{2}$ (range, 4-140 $\mathrm{cm}^{2}$ ), and this might have been due to the prescribed dosage of MTZ $0.75 \%$ gel, that is, once or twice daily and a maximum of $30 \mathrm{~g} /$ day. Mean daily dose was $22.6 \pm 6.4 \mathrm{~g}$, and the daily dosing frequency was $1.46 \pm 0.41$. Therefore, we estimated that mean single dose was approximately $15.5 \mathrm{~g}$, and the mean dose per unit area of skin ulcer was $0.23 \mathrm{~g} / \mathrm{cm}^{2}$. The latter is roughly equivalent to 0.5 fingertip unit (FTU) because 1 FTU, defined as the amount of ointment applied from the distal interphalangeal joint to the tip of the index finger, is approximately equivalent to $0.5 \mathrm{~g}$ 
Table 3 Summary of bacteriological findings $(n=21)$

\begin{tabular}{|c|c|c|}
\hline Category/bacterial species & Baseline day 0 & Post-application \\
\hline Aerobic bacteria & $20(95.2)$ & $19(90.5)$ \\
\hline Acinetobacter baumannii complex & 1 & 0 \\
\hline Aeromonas sp. & 1 & 0 \\
\hline Bacillus sp. & 2 & 1 \\
\hline Citrobacter koseri & 1 & 1 \\
\hline Coagulase(-)staphylococcus & 2 & 1 \\
\hline Corynebacterium sp. & 7 & 8 \\
\hline Enterobacter aerogenes & 1 & 0 \\
\hline Enterobacter cloacae & 2 & 0 \\
\hline Enterococcus durans & 0 & 1 \\
\hline Enterococcus faecalis & 1 & 0 \\
\hline Escherichia coli & 1 & 2 \\
\hline Gemella morbillorum & 1 & 0 \\
\hline Klebsiella pneumoniae & 2 & 1 \\
\hline Proteus mirabilis & 2 & 3 \\
\hline Pseudomonas aeruginosa & 7 & 7 \\
\hline Pseudomonas sp. & 1 & 1 \\
\hline Staphylococcus aureus & 9 & 8 \\
\hline Streptococcus agalactiae (group B) & 3 & 2 \\
\hline$\beta$-Streptococcus (group G) & 0 & 1 \\
\hline Gram-negative aerobic bacteria & 1 & 2 \\
\hline Anaerobic bacteria & $9(42.9)$ & $1(4.8)$ \\
\hline Bacteroides caccae & 1 & 0 \\
\hline Bacteroides fragilis & 1 & 0 \\
\hline Fusobacterium sp. & 1 & 0 \\
\hline Peptostreptococcus asaccharolyticus & 2 & 0 \\
\hline Peptostreptococcus magnus & 2 & 0 \\
\hline Peptostreptococcus micros & 2 & 0 \\
\hline Peptostreptococcus prevotii & 2 & 0 \\
\hline Peptostreptococcus sp. & 0 & 1 \\
\hline Peptostreptococcus tetradius & 2 & 0 \\
\hline Prevotella intermedia & 2 & 0 \\
\hline Streptococcus constellatus & 1 & 0 \\
\hline Streptococcus intermedius & 1 & 0 \\
\hline Gram-negative anaerobic bacteria & 12 & 20 \\
\hline
\end{tabular}

${ }^{\text {a }}$ On day 14 or at the time of premature study termination

[35]. In general, 5 FTU of ointment is needed to treat a skin ulcer of $10 \mathrm{~cm}^{2}$.

By investigator evaluation, improvement of malodor was successful in $95.2 \%(20 / 21)$ of patients. This is consistent with the reported estimate that malodor would improve in $95 \%$ of patients after 2 weeks of MTZ $0.75 \%$ gel by Finlay et al. [12], and verified our study hypothesis that the rate of success in this study would not fall below $70 \%$. Improvement was not successful in one patient after she requested discontinuation of MTZ $0.75 \%$ gel on day 7 because of an increase in exudate. However, improvement of odor was successful in all the patients who completed the 14-day application of the drug. The study of Finley et al. [12] enrolled 20 patients with malodorous fungating tumors, including 13
Table 4 Overall improvement in patient satsfaction $^{\mathrm{a}},(n=21)$

\begin{tabular}{ll}
\hline Category & Number (\%) \\
\hline Markedly improved & $9(42.9)$ \\
Moderately improved & $6(28.6)$ \\
Slightly improved & $5(23.8)$ \\
No change & $1(4.8)$ \\
Worsened & 0 \\
\hline
\end{tabular}

${ }^{\mathrm{a}}$ On day 14 or at the time of premature study termination

breast cancer patients, one for each of oral carcinoma, fungating basal cell carcinoma, carcinoma prostate, malignant ulcer, leg sarcoma, carcinoma tongue, and metastatic carcinoma; malodor was improved in 14 (88\%) of the 16 patients (unpublished data). A similar improvement was observed in Japanese patients in the present study.

Based on the evaluation by patients, nurses, and investigators, the number of patients with a score 2 or above (corresponding to mildly to extremely offensive smell) was 12,17 , and 21 , respectively, on pre-application day 0 , while it was 0,1 , and 1 on day 14 . Olfactory adaptation was believed to be the reason for the small number of patients who gave a score of 2 or above on day 0 compared with the number of nurses and investigators who gave similar scores. The difference between the mean odor score on day 0 and the score on day 14, as assessed by the patients themselves, nurses, and investigators, was respectively $-1.7 \pm 1.1,-2.1 \pm 1.1$, and $-2.2 \pm 0.7$, indicating that the change in odor severity was perceived to be greater by third parties, that is, nurses or investigators, than by patients.

The exudate from fungating wounds changed from being purulent to serous during the course of treatment. This finding is supported by the bacteriological findings that anaerobic bacteria detected in nine patients on day 0 were no longer detectable on day 14 (or at the time of premature study termination), suggesting that MTZ $0.75 \%$ gel effectively reduced the number of anaerobic bacteria in the wounds.

Using the VAS, the mean values of pain were not changed from baseline to day 7 or day 14 . The survey of patient or family satisfaction conducted on day 14 showed that 15 (71.4 \%) patients perceived the effect of MTZ $0.75 \%$ gel on malodor to be quite or very effective, while the survey of nurses or investigators indicated the deodorant effect in all 21 patients was quite or very effective. These findings suggest that all involved parties were satisfied with the effect of MTZ $0.75 \%$ gel.

The results of this study showed that the level of systemic exposure of $\leq 30 \mathrm{~g} \mathrm{MTZ} 0.75 \%$ gel daily for treating a fungating tumor of $4-140 \mathrm{~cm}^{2}$ in size did not exceed the systemic exposure level of $250 \mathrm{mg}$ MTZ taken orally as a 
Table 5 Pharmacokinetic parameters of metronidazole

\begin{tabular}{lllcll}
\hline Parameter & Day of measurement & Number & Mean \pm SD & Median & Range \\
\hline$C_{\max }(\mathrm{ng} / \mathrm{mL})$ & Day 7 & 20 & $852 \pm 697$ & 725 & $136-2872$ \\
$T_{\max }(\mathrm{h})$ & Day 7 & 20 & $3.7 \pm 1.5$ & 3.3 & $2.0-7.2$ \\
Partial AUC $(\mathrm{ng} \bullet \mathrm{h} / \mathrm{mL})$ & Day 7 & 20 & $2955 \pm 2641$ & 2313 & $382-8373$ \\
$C_{\text {trough }}(\mathrm{ng} / \mathrm{mL})$ & Day 7 & 20 & $380 \pm 281$ & 375 & $5-975$ \\
$C_{\text {trough }}(\mathrm{ng} / \mathrm{mL})$ & Day 14 & 20 & $510 \pm 565$ & 303 & $58-2410$ \\
\hline
\end{tabular}

$A U C$ area under the plasma drug concentration-time curve, $C_{\max }$ maximum plasma concentration, $C_{\text {trough }}$ trough value, $T_{\max }$ time required to reach the maximum plasma concentration single dose. In addition, no systemic side effects were observed, demonstrating its safety, provided that the recommended dosage and frequency of administration are followed. The two cases of bleeding from the neoplastic skin lesion, which were considered to be related to MTZ $0.75 \%$ gel, were caused by the dried and solidified gel injuring the ulcer during the dressing change. To prevent such bleeding, the fungating wound and dried MTZ $0.75 \%$ gel should be moistened and softened with clean water before peeling off the dressing.

In summary, this clinical study showed that MTZ $0.75 \%$ gel is safe and highly effective in reducing the intensity of malodors from fungating wounds in breast cancer patients. After 14 days of application, the drug increased levels of satisfaction among the patients, their families, and medical personnel. Finlay et al. [12] reported the efficacy and safety of MTZ $0.75 \%$ gel in malodorous fungating tumors of not only breast cancers but also other cancers. In UK, MTZ $0.75 \%$ gel is indicated for deodorizing malodorous fungating tumors, and topical MTZ used in this study is recommended as the standard drug for malodorous fungating wounds in clinical guidelines $[3,6,7]$. Furthermore, the antibacterial activity of other forms of topical MTZ against anaerobic bacteria has been reported in Japan and overseas. It is therefore reasonable to expect that MTZ $0.75 \%$ gel is safe and effective as a topical agent for malodorous fungating tumors. The commercialization of topical MTZ with proven efficacy, safety, and stability as a formulation will be beneficial even to hospital pharmacists who currently prepare special formulations for their patients.

\section{Compliance with ethical standards}

Funding This study was funded by Galderma. All study drugs were supplied by Galderma.

Conflict of interest Kazuhiro Watanabe, Arata Shimo, Kouichiro Tsugawa, Yutaka Tokuda, Hideko Yamauchi, and Seigo Nakamura declare that they have no conflict of interest. Eriko Miyai, Kimitoshi Takemura, and Akihiko Ikoma are employees of Galderma K.K.

Ethical approval All procedures performed in studies involving human participants were in accordance with the ethical standards of the institutional and/or national research committee and with the 1964
Helsinki Declaration and its later amendments or comparable ethical standards.

Informed consent Informed consent was obtained from all individual participants included in the study.

Open Access This article is distributed under the terms of the Creative Commons Attribution-NonCommercial 4.0 International License (http:// creativecommons.org/licenses/by-nc/4.0/), which permits any noncommercial use, distribution, and reproduction in any medium, provided you give appropriate credit to the original author(s) and the source, provide a link to the Creative Commons license, and indicate if changes were made.

\section{References}

1. Holloway S (2004) Recognising and treating the causes of chronic malodorous wounds. Prof Nurse 19:380-384

2. Paul JC, Pieper BA (2008) Topical metronidazole for the treatment of wound odor: a review of the literature. Ostomy Wound Manage $54: 18-27$

3. The World Health Organization (WHO) (1998) Symptom relief in terminal illness. World Health Organization, Geneva

4. Ashford R, Plant G, Maher J, Teare L (1984) Double-blind trial of metronidazole in malodorous ulcerating tumors. Lancet 1:1232-1233

5. Kuge S, Tokuda Y, Ohta M, et al. (1996) Use of metronidazole gel to control malodor in advanced and recurrent breast cancer. Jpn J Clin Oncol 26:207-210

6. Berger AM, Shuster JL, Von Roenn JH (2007) Principles and practice of palliative care and supportive oncology, 3rd edn. Lippincott Williams \& Wilkins, Philadelphia

7. American Society of Clinical Oncology (2001) Optimizing cancer care: the importance of symptom management, ASCO curriculum skin disorders. Kendall Hunt Publishing Company, Dubuque, Iowa, pp. $1-18$

8. Watanabe K, Shinano H, Tamahashi Y, Nakamura S, Tsuchiya M, Kizu J, Inoue T (2008) Pharmaceutical evaluation of metronidazole external hospital preparation for cancerous malodor. Jpn J Pharm Health Care Sci 34:433-440

9. The Japanese Society of Hospital Pharmacists (2008) 6th edition BYOIN YAKKYOKU SEIZAI, 6th edn. YAKUJI -NIPPO, Tokyo

10. Watanabe K, Tsuchiya M, Shinano H, Nakamura S, Kizu J, Inoue T (2007) A survey about manufactures of ointment preparation inhouse for cancerous malodor in this country. J Jpn Soc Hosp Pharm 43:371-373

11. Watanabe K, Goto N, Sakakibara N, et al. (2011) Survey and research for the commercialization of drugs needed in clinical settings. J Jpn Soc Hosp Pharm 47:949-951(in Japanese) 
12. Finlay IG, Bowszyc J, Ramlau C, Gwiezdzinski Z (1996) The effect of topical $0.75 \%$ metronidazole gel on malodorous cutaneous ulcers. J Pain Symptom Manag 11:158-162

13. Ashino K (2009) The efficacy of metronidazole ointment in treating malodorous tumors. J Jpn Soc Hosp Pharm 45:945-947(in Japanese)

14. Ishiguro T (2001) Pallative care for patients with terminal cancer: management of malodorous tumors using topical agents. Medical and Drug Journal 37:2194-2199(in Japanese)

15. Ueno S (2009) Six cases of palliative home care for patients with progressive recurrent breast cancer. Japanese Journal of Cancer and Chemotherapy 36:78-80(in Japanese)

16. Kono K (2010) The efficacy of metronidazole ointment in treating malodors associated with progressive breast cancer. Japanese Journal of Cancer and Chemotherapy 46:1032-1036(in Japanese)

17. Kumagai H (1999) The efficacy of metronidazole ointment in treating malodors associated with progressive breast cancer. Japanese Journal of Cancer and Chemotherapy 35:3148-3151(in Japanese)

18. Shiga T, Yokogawa M (2009) Two cases of QOL improvement in patients with metastatic skin cancer with concurrent use of Mohs' paste and metronidazole ointment. Nishinihon J Dermatol 71:3841(in Japanese)

19. Suzuki T (2005) Preparation of special hospital formulations to improve patient QOL: management of malodor by metronidazole. Yakuji 47:233-237(in Japanese)

20. Moriya T, Fukatsu K, Ueda S, et al. (2010) A case of massive ulcerating breast cancer cured by successive administrations of epirubicin, cyclophosphamide (EC), and weekly paclitaxel. Med Drug J 37:907-910(in Japanese)

21. Watanabe K, Shinano H, Terajima T, et al. (2008) Pharmaceutical evaluation of new metronidazole gel for cancerous skin ulcer due to advanced breast cancer. Jpn J Breast Cancer 23:105-109(in Japanese)

22. Watanabe K, Shinano H, Tamahashi Y, Nakamura S (2008) The utility of topical metronidazole in treating fungating breast cancer wounds. Med Drug J 44:2430-2434(in Japanese)

23. Iida J, Kudo T, Shimada K, et al. (2013) Investigation of the safety of topical metronidazole from a pharmacokinetic perspective. Biol Pharm Bull 36:89-95
24. Itakura Y, Nagata M, Kitazawa M, Nishida Y (2002) A case of huge squamous cell carcinoma responding to local injection of OK432 (picibanil)/fibrinogen. Aichi Prefectural J Hosp Pharm 30:64-70(in Japanese)

25. Matsuoka A, Ikazaki S, Suemaru K, Wakisaka H, Araki H (2008) Investigation of the effect of metronidazole ointment on malodorous wounds in the head and neck region. Jpn J Pharm Palliat Care Sci 1:67-70(in Japanese)

26. Sagawa K, Matsubara H, Shimada S (1997) Adriamycin and metronidazole ointments. Yakuji 39:995-999(in Japanese)

27. Shinano H, Watanabe K, Nakamura S, Tamahashi Y, Tsuchiya M, Kizu J, Inoue T (2007) The efficacy of topical metronidazole for malodors in progressive recurrent breast cancer. Palliat Care Res 2: 218-222(in Japanese)

28. Suzumura T, Tamiya S, Tamura K, et al. (2012) A case of contact dermatitis syndrome due to metronidazole. Jpn J Clin Dermatol 66: 394-398(in Japanese)

29. Tsubuku M, Tanaka M, Yamaguchi M, et al. (2011) Application of metronidazole gel to control malodor in advanced breast cancer. Jpn J Breast Cancer 26:717-720(in Japanese)

30. Sawada T, Hataike G, Yasuda M, Tamai H, Sakagawa M, Oto I (2009) A patient in whom metronidazole was effective for cancerous malodor related to pleural metastasis, involving the thoracic wall, from gastric cancer. Palliat Care Res 4:339-345(in Japanese)

31. Tsuji T, Kitada H, Abe S (2006) A case of management of malodor using metronidazole in advanced oral cancer patient. Hosp Dent 2: 113-115(in Japanese)

32. Bower M, Stein R, Evance TRJ, Hedley A, Pert P, Coombes RC (1992) A double-blind study of the efficacy of metronidazole gel in the treatment of malodorous fungating tumors. Eur J Cancer 28: 888-889

33. Kalinski C, Schnepf M, Laboy D, et al. (2005) Effectiveness of a topical formulation containing metronidazole for wound odor and exudate control. Wounds 17:84-90

34. Newman V, Allwood M, Oakes RA (1989) The use of metronidazole gel to control the smell of malodorous lesions. Palliat Med 3:303-305

35. Long CC, Finlay AY, Averill RW (1992) The rule of hand: 4 hand areas $=2$ FTU $=1 \mathrm{~g}$. Arch Dermatol 128:1129-1130 